\title{
Muscle Cells: Motor Neuron Targets and Contributors of their Disorders
}

\section{Mariarita Galbiati, Valeria Crippa and Angelo Poletti*}

Dipartimento di Scienze Farmacologiche e Biomolecolari (DiSFeB), Centre of Excellence on Neurodegenerative Diseases, Università degli Studi di Milano, Via Balzaretti 9, 20133 Milano, Italy

Several different neurologic diseases are due to progressive degeneration of the motor neurons, which control voluntary movements by connecting directly to muscles. Among them, Amyotrophic Lateral Sclerosis (ALS), Spinal Muscular Atrophy (SMA), and Spinal Bulbar Muscular Atrophy (SBMA, or Kennedy's disease) are the most common. These motor neuron diseases have different etiology. ALS is typical of adults and could have sporadic or hereditary origin. SMA is an inherited recessive disease linked to mutations in the survival of motor neuron (SMN) gene and has more frequently a child-onset. SBMA is a X-linked disease caused by the expansion of a CAG triplet repeat sequence located in the first exon of the gene coding for the androgen receptor (AR). The molecular mechanisms involved in these diseases differ in the way motor neurons are affected; a defect in protein function causes SMA, while acquisition of aberrant and/or cytotoxic protein activities are at the bases of motor neuron death in ALS and SBMA. By affecting the lower motor neurons (with upper motor neuron involvement only in ALS), these disorders cause the degeneration of neuro-muscular junctions (NMJ), muscle weakness and atrophy.

Till now, the neurocentric view of these disorders was the most accredited, and indicated the motor neuron deficit as the primary site of origin of the diseases. Nevertheless, in the last decade many data indicate an unexpected involvement of the skeletal muscle. This led to reconsider these diseases with a complementary muscle-centric view: muscular deficiency in all these disorders could be also due to a direct muscular toxicity and/or a functional impairment that has denervation and motor neuron death as a consequence.

At the levels of NMJ, transgenic mice models of these disorders allowed to point out early and selective modification of these structures. Changes not only precede motor neuron impairment, but occur at very early pre-symptomatic stages of the diseases. For example, in SMA mice at P1, transcriptome abnormalities (with a great reduction of $\mathrm{Z}^{+}$agrin mRNA that is critical for the postsynaptic organization of the NMJ) suggest that some motor unit could be impaired earlier than NMJ disruptions [1]. In ALS mouse models NMJ degeneration occurs at early stages of disease, and far before the appearance of changes in motor neurons. Skeletal muscle of a transgenic ALS model at early asymptomatic stages ectopically expresses Nogo-A, a neurite outgrowth inhibitor, suggesting that NMJs are morphologically altered $[2,3]$.

At the level of muscle structure and functions evidences demonstrate that both are altered in SMA, ALS, and SBMA. SMN expression is required for the correct formation of sarcomeric $\mathrm{Z}$ disc spacing both in skeletal and cardiac myofibrils, giving an explanation also to the occurrence of congenital heart defects in SMA. Decreased proliferation and reduced functionality of myoblasts are present in SMA animal models [4]. Also ALS satellite cell properties are altered, contributing to initiation and progression of muscle atrophy $[5,6]$. Alterations in muscle gene expression are present pre-symptomatically in ALS $[7,8]$. The AR, highly expressed on muscle where it has potent anabolic activities, when mutated in SBMA exerts its toxicity directly in muscle cells $[9,10]$. SBMA patients have a reduced number of myotube nuclei, suggestive of an impaired process of myofiber fusion [11].

Despite the fact that the view of muscle as primary site for disease pathogenesis in motor neuron disorders is still largely debated and not yet completely cleared, the discovery of muscle as a crucial site for initiation of motor neuron pathologies raises the possibilities of new and complementary therapies. Indeed, several advantages may arise from these observations, being muscle more easily targeted with pharmacological or genetic approaches than motor neuronal cells. In SMA mice a significant improvement in survival and motor behavior has been reported with muscle-specific conditional rescue [12], or muscle delivery of antisense oligonucleotide (ASO) re-establishing the levels of expression of SMN2 gene [13]. Furthermore, ASO silencing AR gene expression only in periphery, and not in motor neurons, rescued the phenotype and extended the lifespan of male SBMA mice, proving the muscle toxicity of the mutant AR [14]. Beneficial effects in these motor neurons disorders have been obtained also with IGF-I. This growth factor supports motor neurons survival, preserves NMJ and diminishes muscle atrophy in ALS mice [15]; in the same way, muscledirected expression of IGF-1 can rescue systemic and neuromuscular phenotypes in SBMA mice both via trophic activities on motor neurons and counteracting ARpolyQ muscle toxicity [16].

From data of literature, including ours, it may be proposed that muscle degeneration in motor neuron disorders is not only due to motor neuron death, but also to intrinsic changes in myoblasts, and to alteration of muscular structure and function. The selective direct damages of muscular cells may be responsible for variation in onset and/or progression of these motor neuron diseases, and it might be possible that motor neurons diseases could also be initiated with skeletal muscle damage, rather than specific alteration in spinal cord motor neurons. To recognize muscle as a primary site of dysfunction might have important implications not only to clarify the molecular mechanisms underlying motor neurons disorders, but also to develop new therapeutical strategies to treat or, at least, to delay muscle wasting.

\section{References}

1. Zhang Z, Pinto AM, Wan L, Wang W, Berg MG, et al. (2013) Dysregulation of synaptogenesis genes antecedes motor neuron pathology in spinal muscular atrophy. Proc Natl Acad Sci U S A 110: 19348-19353.

${ }^{*}$ Corresponding author: Angelo Poletti, Dipartimento di Scienze Farmacologiche Biomolecolari, Centre of Excellence on Neurodegenerative Diseases, Università degli Studi di Milano, Italy, Tel: +390250318215; E-mail: angelo.poletti@unimi.it

Received May 28, 2015; Accepted June 04, 2015; Published June 10, 2015

Citation: Galbiati M, Crippa V, Poletti A (2015) Muscle Cells: Motor Neuron Targets and Contributors of their Disorders. Brain Disord Ther 4:e121. doi:10.4172/2168-975X.1000e121

Copyright: (c) 2014 Galbiati M, et al. This is an open-access article distributed under the terms of the Creative Commons Attribution License, which permits unrestricted use, distribution, and reproduction in any medium, provided the original author and source are credited. 
Citation: Galbiati M, Crippa V, Poletti A (2015) Muscle Cells: Motor Neuron Targets and Contributors of their Disorders. Brain Disord Ther 4:e121. doi:10.4172/2168-975X.1000e121

Page 2 of 2

2. Bruneteau G, Bauché S, Gonzalez de Aguilar JL, Brochier G, Mandjee N, et al. (2015) Endplate denervation correlates with Nogo-A muscle expression in amyotrophic lateral sclerosis patients. Ann Clin Transl Neurol 2: 362-372.

3. Dupuis L, Gonzalez de Aguilar JL, di Scala F, Rene F, de Tapia M, et al. (2002) Nogo provides a molecular marker for diagnosis of amyotrophic lateral sclerosis. Neurobiol Dis 10: 358-365.

4. Martínez-Hernández R, Soler-Botija C, Also E, Alias L, Caselles L, et al. (2009) The developmental pattern of myotubes in spinal muscular atrophy indicates prenatal delay of muscle maturation. J Neuropathol Exp Neurol 68: 474-481.

5. Pradat PF, Barani A, Wanschitz J, Dubourg O, Lombès A, et al. (2011) Abnormalities of satellite cells function in amyotrophic lateral sclerosis. Amyotroph Lateral Scler 12: 264-271.

6. Manzano R, Toivonen JM, Oliván S, Calvo AC, Moreno-Igoa M, et al. (2011) Altered expression of myogenic regulatory factors in the mouse model of amyotrophic lateral sclerosis. Neurodegener Dis 8: 386-396.

7. Galbiati M, Crippa V, Rusmini P, Cristofani R, Cicardi ME, et al. (2014) ALSrelated misfolded protein management in motor neurons and muscle cells. Neurochem Int 79: 70-78

8. Galbiati M, Onesto E, Zito A, Crippa V, Rusmini P, et al. (2012) The anabolic/ androgenic steroid nandrolone exacerbates gene expression modifications induced by mutant SOD1 in muscles of mice models of amyotrophic latera sclerosis. Pharmacol Res 65: 221-230.

9. Cortes CJ, Ling SC, Guo LT, Hung G, Tsunemi T, et al. (2014) Muscle expression of mutant androgen receptor accounts for systemic and motor neuron disease phenotypes in spinal and bulbar muscular atrophy. Neuron 82: 295-307.

10. Yu Z, Dadgar N, Albertelli M, Gruis K, Jordan C, et al. (2006) Androgendependent pathology demonstrates myopathic contribution to the Kennedy disease phenotype in a mouse knock-in model. J Clin Invest 116: 2663-2672.

11. Malena A, Pennuto M, Tezze C, Querin G, D’Ascenzo C, et al. (2013) Androgendependent impairment of myogenesis in spinal and bulbar muscular atrophy. Acta Neuropathol 126: 109-121.

12. Martinez TL, Kong L, Wang X, Osborne MA, Crowder ME, et al. (2012) Survival motor neuron protein in motor neurons determines synaptic integrity in spinal muscular atrophy. J Neurosci 32: 8703-8715.

13. Hua Y, Sahashi K, Rigo F, Hung G, Horev G, et al. (2011) Peripheral SMN restoration is essential for long-term rescue of a severe spinal muscular atrophy mouse model. Nature 478: 123-126.

14. Lieberman AP, Yu Z, Murray S, Peralta R, Low A, et al. (2014) Periphera androgen receptor gene suppression rescues disease in mouse models of spinal and bulbar muscular atrophy. Cell Rep 7: 774-784.

15. Dobrowolny G, Giacinti C, Pelosi L, Nicoletti C, Winn N, et al. (2005) Muscle expression of a local lgf-1 isoform protects motor neurons in an ALS mouse model. J Cell Biol 168: 193-199.

16. Palazzolo I, Stack C, Kong L, Musaro A, Adachi H, et al. (2009) Overexpression of IGF-1 in muscle attenuates disease in a mouse model of spinal and bulbar muscular atrophy. Neuron 63: 316-328. 